\title{
RESTRICCIONES DE LA ELIPSIS NOMINAL EN ESPAÑOL ${ }^{1}$
}

\author{
LUIS EGUREN \\ Universidad Autónoma de Madrid
}

\section{RESUMEN}

En este trabajo se estudian las condiciones que regulan la buena formación de las expresiones nominales con elipsis en español. Se demuestra, en primer lugar, que no es necesaria la presencia ni de un determinante ni de marcas de género o número para que la elipsis sea posible y se defiende, además, la idea de que la elipsis nominal está sujeta a dos condiciones semánticas: por un lado, el sintagma nominal elíptico debe remitir a un tópico discursivo y, por otro, el material no omitido tiene que recibir una interpretación de foco contrastivo. Estas dos condiciones nos permiten explicar, en concreto, qué determinantes y clases de adjetivos admiten la elipsis nominal y cuáles la rechazan.

Palabras clave: adjetivos, determinantes, elipsis nominal, foco contrastivo, morfología nominal, partitividad, tópico discursivo.

\section{Abstract}

In this paper the licensing conditions on nominal ellipsis in Spanish are addressed. It is first shown that neither the presence of a determiner nor the display of gender and/or number markers on the remnant is a necessary condition for nominal ellipsis to occur, and it is also claimed that nominal ellipsis obeys two semantic conditions: the elliptical nominal has to refer to a discourse topic and the non elided material must be interpreted as contrastive focus. These two conditions help us explain why certain determiners and certain classes of adjectives are compatible with nominal ellipsis while others are not.

Key Words: contrastive focus, determiners, discourse topic, nominal ellipsis, nominal morphology, partitivity.

\section{INTRODUCGIÓN}

El análisis de sintagmas nominales como los que aparecen entre corchetes en los ejemplos de (1) es, como se sabe, uno de los asuntos más

\footnotetext{
${ }^{1}$ Marina Fernández Lagunilla, Inés Fernández Ordóñez, Olga Fernández Soriano, Manuel Leonetti, Alberto Morón, José Portolés y Cristina Sánchez han tenido la amabilidad de leer versiones anteriores de este trabajo y lo han mejorado con sus sugerencias. Vaya para todos ellos mi agradecimiento. Solo yo soy responsable de los errores que aún contenga el texto. Este trabajo ha sido parcialmente financiado por medio de la subvención al proyecto EDU2008-01268 y de la ayuda del Plan de Movilidad del Profesorado Universitario PR2008-0005.
} 
debatidos en los estudios sobre la gramática del español²:

(1) a. Las hojas verdes y [las rojas $]_{\mathrm{SN}}$

b. Las hojas de la higuera y [las del cerezo $]_{\mathrm{SN}}$

c. Las hojas que recogí y [las que aún quedan en el jardín $]_{\mathrm{SN}}$

(2) a. $\left[\operatorname{las}_{\text {Det }} \text { rojas }\right]_{\mathrm{SN}}$

b. $\left[\operatorname{las}_{\text {Pron }} \text { rojas }\right]_{\mathrm{SN}}$

c. $\left[\operatorname{las}_{\text {Det }} v_{\mathrm{N}} \text { rojas }\right]_{\mathrm{SN}}$

d. $\left[\operatorname{las}_{\text {Det }} \text { trojas }_{\mathrm{N}} \text { rojas }\right]_{\mathrm{SN}}$

Para quienes optan por la «hipótesis sustantivadora», estas expresiones carecen de núcleo nominal (son exocéntricas) y en ellas el artículo es un determinante que actúa como transpositor y convierte al conjunto en un sustantivo - cf. (2a) $-^{3}$. Otros autores defienden la llamada "hipótesis de la pronominalización», representada en (2b), y sostienen que en estos sintagmas nominales el artículo es un pronombre y encabeza la construcción ${ }^{4}$. Algunos lingüistas consideran, por último, que en los sintagmas nominales entre corchetes de (1) se sobreentiende el contenido descriptivo de un sustantivo que no tiene realización fonética ${ }^{5}$. Esta idea (la «hipótesis de la elipsis») se ha formulado de dos maneras distintas. Una de ellas, el «análisis con reconstrucción» de (2c), consiste en suponer que los SSNN con elipsis tienen como núcleo una categoría sintáctica nominal desprovista de contenido fónico (una «categoría vacía» = v), cuyo contenido se recupera (se reconstruye) contextualmente a la hora de obtener la interpretación semántica de la construcción ${ }^{6}$. En el «análisis con borrado» de (2d), en cambio, la falta de realización fonética del núcleo de la expresión nominal es el resultado de la aplicación de una regla fonética de elisión (o borrado), que opera bajo criterios de identidad estricta entre los rasgos del elemento borrado y los de su antecedente ${ }^{7}$.

${ }^{2}$ No deben confundirse estos ejemplos con los casos de «sustantivación léxica» (los sordos) o de SSNN sin un sustantivo expreso que se refieren de forma genérica a personas y que no remiten anafóricamente a ningún antecedente (los de Valladolid), de los que no hablaré aquí.

${ }^{3}$ En una versión distinta de la hipótesis sustantivadora, el artículo nominaliza al elemento que lo acompaña. Entre los defensores de la hipótesis sustantivadora están, entre otros, Alarcos 1970, Gutiérrez Ordóñez 1994, Iglesias Bango 1986 y Jiménez Juliá 1991.

${ }^{4}$ Véase, p. ej., Bello 1847, Bosque y Moreno 1990, Briz 1989 y Fernández Ramírez 1951.

${ }^{5}$ Cf. Alonso y Henríquez Ureña 1938 y Lázaro Carreter 1975.

${ }^{6}$ Cf., p. ej., en la tradición gramatical española más reciente, Bosque 1989, Brucart 1987a,b, 1999, Contreras 1989, 1992, Eguren 1989, Hernanz y Brucart 1987, Llombart-Huesca 2002 y Torrego 1989.

${ }^{7}$ Cf. Lázaro Carreter 1975, en el marco del Modelo Estándar de la gramática generativa, y más recientemente (entre los estudiosos de la gramática del español), Kornfeld y Saab 2004, Masullo y Depiante 2003, Saab 2004 y Ticio 2005. Los análisis de (2) se suelen aplicar también de manera uniforme a los casos de expresiones nominales equivalentes introducidas por determinantes distintos del artículo determinado, con una excepción: hay quien adopta la hipótesis sustantivadora solo en el caso del artículo definido y considera que el resto de los determinantes funciona como pronombres. 
En estas páginas no revisaré los argumentos que se han presentado a favor o en contra de cada una de estas propuestas de análisis (tan solo en las conclusiones comentaré brevemente la incidencia que en este debate podrían tener los datos que serán sometidos a examen), y adoptaré sin más discusión una de las versiones de la hipótesis de la elipsis nominal: el análisis con reconstrucción.

El debate sobre la naturaleza de las expresiones nominales encorchetadas de (1) se ha centrado a menudo en cuestiones de carácter más bien teórico (la legitimidad de las operaciones de cambio de categoría, la universalidad del requisito de que todos los sintagmas tengan un núcleo o el supuesto problema de la duplicación de categorías), pero no han sido analizadas de manera sistemática y exhaustiva sus propiedades específicas. Mi objetivo es, precisamente, cubrir este hueco. En el marco que he adoptado, el de la hipótesis de la elipsis nominal, estudiaré con detalle las condiciones que regulan la buena formación de los sintagmas nominales con núcleo elidido en español e intentaré dar respuesta, en concreto, a las siguientes preguntas:

(a) ¿Se requiere la presencia de un determinante en las construcciones con elipsis nominal? (Un ejemplo como el de (3a) parece indicar que la aparición del determinante es obligatoria, mientras que el ejemplo de (3b) nos lleva a pensar justamente lo contrario):

(3) a. Juan es tío de María y Pedro es *(tío) de Ana.

b. Primero estuvimos viendo fotos antiguas y luego vimos (fotos) de ahora.

(b) ¿Qué papel desempeña la morfología de género y número en la buena formación de los sintagmas nominales con núcleo tácito? (El dato de (4a) sugiere que cumple una función relevante, pero datos como los de (4b) nos hacen dudar de que esto sea realmente así):

(4) a. Yo he visitado estas ciudades. ¿Qué * (ciudades) has visitado tú?

b. Dos políticos del PSOE se llevan bien con distint-os *(políticos) del PP.

(c) ¿Por qué solo ciertos determinantes introducen un SN con núcleo vacío?

(5) a. Se dice que todos (los españoles) se echan la siesta después de comer. b. Se dice que todo * (español) se echa la siesta después de comer.

(d) ¿Cuál es la causa de que algunas clases de adjetivos sean incompatibles con la elipsis nominal? (Los adjetivos restrictivos, por ejemplo, admiten la elisión del núcleo nominal y los adjetivos no restrictivos la rechazan):

(6) a. Llegaron a la cima los (montañeros) entrenados. b. Llegaron a la cima los entrenados *(montañeros). 
En este trabajo defenderé la idea de que no es necesaria la presencia ni de determinantes ni de marcas flexivas para legitimar la elipsis nominal en español y que la buena formación de estas construcciones responde a dos condiciones de naturaleza semántica: el requisito de que los SSNN con elipsis tengan que estar vinculados con el discurso para que pueda recuperarse el contenido del sustantivo omitido y el hecho de que el «resto» (esto es, el material no elidido) deba recibir una interpretación contrastiva.

\section{ANÁlisis FORMALES Y TEORÍAS SEMÁNTICAS}

En los últimos veinte años se han formulado propuestas de distinto signo acerca de las restricciones que pesan sobre los sintagmas nominales con núcleo elíptico tanto en español como en otras lenguas. Dichas propuestas podrían quedar agrupadas en dos grandes bloques: existe, por un lado, un buen número de análisis estrictamente formales; algunos lingüistas sostienen, por otro, que la elipsis nominal está sujeta a condiciones semánticas de buena formación ${ }^{8}$.

En los análisis formales de la elipsis nominal, la presencia de sustantivos sin realización fonética se hace depender de dos condiciones que para la mayoría de los autores deben operar juntas: (a) la presencia en el resto del SN con elipsis de algún elemento léxico que legitime estructuralmente el nominal vacío y (b) la aparición, también en el resto, de marcas flexivas explícitas que permitan recuperar el contenido del material elidido ${ }^{9}$.

La propuesta de Lobeck 1995 es el ejemplo más representativo de este enfoque. Esta lingüista asume que las categorías vacías deben ajustarse a dos tipos de condiciones de buena formación -las «condiciones de legitimación», que restringen su distribución, y las «condiciones de identificación», que permiten recuperar su contenido-, y supone, además, que la categoría sin realización fonética que se genera en la posición de núcleo en un SN elíptico es el mismo pronominal vacío (pro) que, en la tradición generativista, ocupa la posición de sujeto en las oraciones temporalizadas con sujeto tácito. Propone Lobeck, por último, que en todas las construcciones en las que aparece la categoría vacía pro se debe respetar la condición de (7):

\footnotetext{
${ }^{8}$ En Lobeck 2006 puede encontrarse una revisión histórica de las distintas propuestas sobre la elipsis nominal elaboradas dentro del marco generativista.

${ }^{9}$ Como se verá a continuación, estas dos condiciones se combinan en el análisis de Lobeck 1995. Bernstein 1993 y Kester 1996 presentan, en cambio, análisis formales de la elipsis nominal en los que se destaca uno de estos dos factores. Para Bernstein, un sustantivo elidido puede estar regido por una categoría funcional Marca de Palabra. Kester considera, por su parte, que un factor relevante en la legitimación de nominales vacíos es la presencia de morfología flexiva adjetival rica en el resto.
} 
(7) Legitimación e identificación de pro:

Una unidad pronominal tácita debe estar regida propiamente por un núcleo con marcas fuertes de concordancia ${ }^{10}$.

En el caso de los sintagmas nominales con núcleo elíptico en concreto, pro estaría legitimado estructuralmente por un elemento rector situado en la posición de $\mathrm{D}$ (eterminante) y quedaría identificado por las marcas fuertes de concordancia de dicho determinante ${ }^{11}$. Lobeck 1995 atribuye, en suma, un papel muy relevante en la buena formación de los sintagmas nominales con núcleo elíptico al hecho de que el sustantivo elidido esté precedido por un determinante que posea marcas de flexión fonéticamente realizadas ${ }^{12}$. Datos como los de (8) y (9) avalan, a primera vista, esta idea:

(8) a. *Luis es traductor de Oscar Wilde y Antonio es $[\mathrm{v}]_{\mathrm{N}}$ de Joyce. b. *Juan es tío de María y Pedro es [v] ${ }_{\mathrm{N}}$ de Ana.

(9) a. The students from Paris and the *(ones) from Madrid.

b. Los estudiantes de París y los $[\mathrm{v}]_{\mathrm{N}}$ de Madrid.

En $(8 \mathrm{a}, \mathrm{b})$ no aparece ningún determinante en el predicado nominal con elipsis de la segunda oración coordinada y el resultado es agramatical. Este hecho parece indicar que la presencia del determinante es obligatoria en las construcciones nominales con núcleo elíptico. El contraste de (9) entre los sintagmas nominales con núcleo omitido y artículo determinado del inglés y del español podría atribuirse, a su vez, a que el artículo tiene flexión de número en español, mientras que en inglés es una categoría invariable.

Frente a los análisis estrictamente formales de la elipsis nominal, en los últimos años se han formulado propuestas alternativas en las que la buena formación de los sintagmas nominales con núcleo elíptico se atribuye a condiciones de naturaleza semántica.

La primera y más básica condición semántica que deben respetar de manera universal las construcciones con elipsis nominal para poder estar bien formadas es que el contenido del constituyente elidido tiene que poder ser identificado de manera inequívoca a partir de información contextual:

\footnotetext{
${ }^{10}$ Lobeck identifica la «concordancia fuerte» con la manifestación morfológica productiva de rasgos y supone que son concordancia fuerte de D en inglés los rasgos [+plural], [+posesivo] y [+partitivo]. No se discutirán aquí los detalles de esta propuesta, que presenta algunos problemas serios: el rasgo [+partitivo], por ejemplo, es un rasgo puramente semántico, que no tiene ninguna «manifestación morfológica productiva».

${ }^{11}$ Lobeck 1995 hace uso de la llamada «Hipótesis del Sintagma Determinante», según la cual el determinante es canónicamente el núcleo de las secuencias formadas por un determinante y un nombre común. Comparto plenamente esta idea, pero, por razones meramente expositivas, en este trabajo se empleará, como norma general, el término tradicional de «Sintagma Nominal».

${ }^{12}$ Son también de esta opinión gran parte de los lingüistas que han estudiado la elipsis nominal en español: cf., p. ej., Brucart 1987a,b, 1999, Contreras 1989, 1992, Eguren 1989, Kornfeld y Saab 2004, Saab 2004 y Torrego 1989.
} 
(10) Condición de recuperabilidad del contenido descriptivo en la elipsis nominal:

El contenido de una categoría nominal elidida ha de ser recuperado por medio de información aportada por el contexto discursivo o situacional.

Algunos linguistas parten de este hecho y recurren a nociones semánticas como la «partitividad» o la «vinculación discursiva» (D-linking) para dar cuenta de la buena o mala formación de los SSNN con elipsis ${ }^{13}$. Estos autores consideran que dichos SSNN constituyen siempre un subconjunto de una clase accesible en el contexto lingüístico o extralingüístico, lo cual hace posible que no se necesite mencionar de nuevo la clase en cuestión. Así se explicaría, por ejemplo, que las expresiones elípticas de (11) y (12) sean gramaticales tanto en español como en inglés, aunque los cardinales no tengan flexión de número en ninguna de las dos lenguas y el artículo y el adjetivo sean categorías invariables en inglés:

(11) a. Cuando estuvimos en Italia, yo visité dos ciudades y Ana visitó tres $[\mathrm{v}]_{\mathrm{N}}$.

b. When we were in Italy, I visited two cities and Ann visited three $[\mathrm{v}]_{\mathrm{N}}$.

(12) a. A María le fascinan esos manuscritos. Su favorito es el $[v]_{N}$ más viejo.

b. Mary is fascinated by those manuscripts. Her favourite is the oldest $[\mathrm{v}]_{\mathrm{N}}$.

Los numerales cardinales y los superlativos analíticos hacen una partición en un conjunto de referencia consabido. De ahí que no haga falta expresar explícitamente la clase descriptiva de que se trate.

Junto al hecho de que el contenido descriptivo del sustantivo elidido deba ser recuperado, otra propiedad semántica de los SsNN con núcleo elíptico es que, para que la elipsis sea lícita, tiene que producirse un contraste entre el «antecedente»y lo que resta en el SN con el nominal elidido $^{14}$. O dicho de otro modo, el resto de un sN con elipsis debe recibir una interpretación de foco contrastivo, de manera que siempre ha de aparecer o suponerse una alternativa a tales elementos focalizados en el contexto ${ }^{15}$. Esta es la causa de que sea anómala una oración como la de (13a) y esté bien formada, en cambio, la oración de (13b):

(13) a. *Juan ha leído dos cuentos de Borges y yo he leído dos $[\mathrm{v}]_{\mathrm{N}}$ de Borges.

b. Juan ha leído dos cuentos de Borges y yo he leído tres $[\mathrm{v}]_{\mathrm{N}}$ de Cortázar.

${ }^{13}$ Cf., p. ej., Bouchard 2002, López 2000, Martinho 1998 y Sleeman 1993, 1996. Hay que precisar, sin embargo, que Sleeman y López, en concreto, no se apartan del todo de los análisis formales de la elipsis nominal: para estos lingüistas, el sustantivo elidido debe también estar regido en la estructura, aunque, en su caso, el elemento rector o bien tiene un significado partitivo o bien vincula el SN con un tópico discursivo (cf. § 5.2).

${ }^{14}$ Véase Corver y van Koppen 2005, Giannakidou y Stavrou 1999 y Ntelitheos 2004.

${ }^{15}$ Sobre el concepto de «foco» como elección en un conjunto predeterminado de alternativas equivalentes véase Rooth 1992, 1996. 
En las páginas que siguen se comparan, a la luz de los datos del español, los análisis formales de la elipsis con los análisis semánticos. En contra de los postulados de los análisis formales, mostraré, en primer lugar, que no es necesaria en nuestra lengua ni la presencia del determinante ni la aparición de marcas flexivas nominales en el resto para legitimar o identificar un sustantivo elidido. A continuación, estudiaré con detalle el papel que en los SSNN con elipsis del español desempeñan el foco contrastivo y nociones como la partitividad o la vinculación discursiva a la hora de explicar qué determinantes y qué clases de adjetivos admiten la elipsis nominal y cuáles la rechazan.

\section{LA PRESENCIA DEL DETERMINANTE}

En los estudios sobre la elipsis nominal en español es frecuente encontrar la afirmación de que en estas construcciones debe aparecer obligatoriamente un determinante con realización fonética. Sin embargo, se puede constatar que la elipsis nominal con nombres escuetos continuos o discontinuos en plural es perfectamente posible en nuestra lengua en contextos tanto discursivos (14), como situacionales $(15)^{16}$.

(14) a. Nunca bebo cerveza caliente. Solo bebo $[v]_{N}$ fría.

b. Primero estuvimos viendo fotos antiguas y luego vimos $[\mathrm{v}]_{\mathrm{N}}$ de ahora.

(15) (Haciendo la compra, ante un surtido de mandarinas de distinto tipo): a. Dame $[\mathrm{v}]_{\mathrm{N}}$ pequeñas.

b. Dame $[\mathrm{v}]_{\mathrm{N}} \sin$ pepitas.

Una conclusión importante que cabe extraer de estos datos es que no es imprescindible que existan piezas léxicas con morfología flexiva nominal (de número y/o género) en el resto de un sintagma nominal con elipsis para que pueda omitirse el sustantivo. Como muestran algunos de los ejemplos de (14)-(15), y como se ilustra en (16), la elipsis nominal se puede producir también en el caso de nombres escuetos modificados por sintagmas preposicionales u oraciones de relativo, que son invariables:

(16) a. No había leído novelas de Cela, pero sí había leído $[\mathrm{v}]_{\mathrm{N}}$ de Delibes.

b. Luis solo compra coches que corran mucho, pero yo prefiero com$\operatorname{prar}[\mathrm{v}]_{\mathrm{N}}$ que corran poco.

La situación es más compleja, no obstante, cuando se trata de llegar a una conclusión definitiva a partir de datos como los de (14)-(16) en lo que respecta a la supuesta obligatoriedad del determinante en los SSNN con núcleo tácito. Los datos que acabo de presentar muestran que la elipsis nominal es posible con determinados nombres escuetos, pero el problema está en que de aquí no se deduce necesariamente

\footnotetext{
${ }^{16}$ Este hecho ya había sido observado por Bosque 1989 y Leonetti 1999.
} 
que el determinante esté ausente en los ssnN con núcleo elíptico. De hecho, algunos autores han propuesto que las construcciones con nombres escuetos que nos ocupan están encabezadas por un determinante implícito con la interpretación de un cuantificador existencial ${ }^{17}$. Si este análisis fuera correcto, se podría pensar que el sustantivo elidido en las construcciones con esta clase de nombres escuetos está también regido (y queda formalmente legitimado) por un determinante, que en este caso no tiene realización fonética.

Otros autores rechazan, sin embargo, que en estas construcciones intervenga un cuantificador vacío (véase, p. ej., Borer 2005 y Laca 1996, 1999). Uno de los argumentos más convincentes a favor de esta idea es que el comportamiento de estos nombres escuetos no coincide con el de las expresiones cuantificadas. Laca 1999 nos ofrece dos pruebas al respecto (entre otras). En primer lugar, los nombres escuetos admiten la cuantificación adverbial mediante expresiones como en exceso (17a), que aparecen en el predicado de una oración pero cuantifican la relación que existe entre el predicado y uno de sus argumentos de modo similar a como lo hacen los cuantificadores adnominales (17b). En cambio, dado que no es lícito cuantificar dos veces la misma entidad, la cuantificación adnominal es incompatible con este tipo de cuantificación adverbial (17c). La gramaticalidad de la oración de (17a) nos indica, por tanto, que no puede ser cierto que los nombres escuetos que nos ocupan vayan acompañados de un cuantificador tácito: de ser así, esta oración debería estar mal formada, como lo está la oración de (17c).

(17) a. Beber vino en exceso es peligroso.

b. Beber demasiado vino es peligroso.

c. *Beber algo de vino en exceso es peligroso.

En segundo lugar, los sintagmas nominales cuantificados, al igual que las expresiones referenciales, aparecen en contextos perfectivos o télicos, que marcan el punto final de un evento, como los creados por un «reflexivo perfectivo» o por un sintagma preposicional con valor temporal encabezado por la preposición en (18a). Los nombres escuetos continuos o discontinuos en plural forman parte, en cambio, de predicados imperfectivos o atélicos y no pueden aparecer en estos mismos contextos (18b). Por lo tanto, si fuera cierto que estos nombres escuetos están introducidos por un cuantificador nulo, el contraste de (18) no debería producirse.

(18) a. Juan se bebió \{el/un montón de\} café en un minuto.

b. *Juan se bebió café en un minuto.

Estas diferencias entre los nombres escuetos continuos y discontinuos en plural y las expresiones cuantificadas muestran que la presencia de cuantificadores nulos en las construcciones con dichos nombres es,

${ }^{17}$ Véase, p. ej., Contreras 1986, 1996 y Longobardi 1994. 
cuanto menos, dudosa. Ahora bien, si el nombre elidido no está formalmente regido por un determinante, ¿cómo es posible entonces la elipsis en los sintagmas nominales con estos nombres escuetos? La respuesta a esta pregunta es, a mi entender, semántica y guarda relación con el concepto de «partitividad». Los modificadores restrictivos de un núcleo nominal vacío establecen una partición en una entidad continua o en un conjunto de individuos. Para que esta operación de partición pueda llevarse a cabo, se debe presuponer que existe un conjunto de referencia en el contexto lingüístico o extralingüístico y, de este modo, el contenido descriptivo del sustantivo elidido puede ser recuperado de manera inequívoca. En el apartado V se mostrará el relevante papel que la relación semántica de partitividad o inclusión desempeña en la recuperación del contenido descriptivo de los nominales vacíos que están introducidos por un determinante. No parece descabellado proponer, por tanto, que esta relación entre conjuntos y subconjuntos de una misma clase es también la propiedad semántica que permite la elisión del núcleo nominal en los nombres escuetos continuos o discontinuos en plural.

La noción de partitividad nos ayuda a explicar, además, por qué la elipsis está vetada en casos de ausencia del determinante con nombres escuetos en función de predicado nominal:

(19) a. *Luis es traductor de Oscar Wilde y Antonio es $[\mathrm{v}]_{\mathrm{N}}$ de Joyce.

b. *Juan es tío de María y Pedro es $[\mathrm{v}]_{\mathrm{N}}$ de Ana.

Estas oraciones no son agramaticales porque los nombres escuetos con elipsis en cuestión carezcan de un determinante que pueda regir formalmente al sustantivo elidido (nótese que no existe en estos casos justificación semántica alguna para postular la presencia de un cuantificador vacío). Lo son porque, en estas oraciones copulativas, se adscribe un individuo a una clase y los modificadores del nominal vacío no extraen una parte de un conjunto contextualmente determinado, sino que especifican con mayor precisión dicha clase. En estas construcciones no se presupone, por tanto, la existencia de un conjunto de referencia y el contenido descriptivo del sustantivo omitido no puede ser recuperado.

En esta sección he querido demostrar que los datos de elipsis nominal con nombres escuetos continuos o discontinuos en plural avalan la idea de que la elisión de núcleos nominales no requiere la presencia de un determinante. Estos mismos datos nos indican, además, que tampoco se necesita que aparezcan marcas flexivas (de género o número) en el resto de un SN elíptico. La función que cumple la morfología de género y número en la elipsis nominal se analiza con más detalle a continuación. 


\section{El PAPEL DE LA MORFOLOGÍA DE GÉNERO Y NÚMERO}

Una opinión compartida por la mayoría de los estudiosos de la elipsis nominal en español es que la morfología flexiva de los determinantes (y, en particular, el morfema de número) desempeña un papel fundamental en la recuperación del material elidido, hasta el punto de que se ha afirmado que su presencia resulta imprescindible para que pueda producirse la elipsis. Sin embargo, datos como los de (20) muestran claramente que no basta con que el sN elíptico contenga un determinante con marcas de género o número para que pueda omitirse un núcleo nominal. En estas secuencias, el determinante está flexionado, pero la elipsis no es posible:

(20) a. *Dos estudiantes de literatura han discutido con distint-as $[\mathrm{v}]_{\mathrm{N}} \mathrm{de}$ lengua.

b. *Dos políticos del Psoe se llevan bien con ciert-os $[\mathrm{v}]_{\mathrm{N}}$ del PP.

No es difícil encontrar también ejemplos del supuesto contrario, esto es, ssNn en los que es lícito omitir el núcleo nominal aunque no haya marcas de morfología flexiva en el resto. Como se decía en el apartado anterior, esto es lo que ocurre en los casos de elipsis nominal en nombres escuetos modificados por un SP o una oración de relativo (21), y así sucede igualmente en los SSNN con núcleo tácito de (22), que están introducidos por determinantes invariables, como los numerales cardinales (distintos de uno) o los comparativos de desigualdad más y menos:

(21) a. No había leído novelas de Cela, pero sí había leído [v] $]_{N}$ de Delibes.

b. Dame $[\mathrm{v}]_{\mathrm{N}}$ que sepan a mandarina de verdad.

(22) a. En el congreso Juan escuchó tres comunicaciones y yo escuché dos $[\mathrm{v}]_{\mathrm{N}}$.

b. La gente bebe poca agua y debería beber bastante más $[\mathrm{v}]_{\mathrm{N}}$.

Los datos que estoy comentando contradicen uno de los postulados básicos de los análisis estrictamente formales de la elipsis nominal. Refutan, en concreto, la idea de que los núcleos nominales elididos tengan que ser «identificados» por rasgos flexivos explícitos: como acabamos de ver, la aparición de morfología flexiva en el resto no solo no es suficiente, sino que ni siquiera es necesaria para recuperar el contenido del sustantivo elidido.

Otra prueba de que la presencia de marcas morfológicas de número en el resto no desempeña, en realidad, papel alguno en la identificación del contenido descriptivo elidido es que puede perfectamente haber un desajuste en número entre el sustantivo elidido y su antecedente ${ }^{18}$ :

\footnotetext{
${ }^{18}$ El género del sustantivo elidido y el género de su antecedente deben ser, en cambio, idénticos: *El hijo de Ana y la [v] $]_{N}$ de María están en la misma clase, * Este gato es mucho más cariñoso que esa $[v]_{N^{*}}$ De aquí no se desprende que las marcas de género sean imprescindibles para recuperar el contenido de un sustantivo elidido (recuérdense los datos de elipsis nominal de (21) y (22), en los que el resto no contiene marcas de género). Lo que este contraste entre la morfología
} 
(23) a. El hijo de Ana y los [v $]_{\mathrm{N}}$ de María están en la misma clase.

b. Estos gatos son mucho más cariñosos que ese $[\mathrm{v}]_{\mathrm{N}}$.

Ahora bien, afirmar que la morfología flexiva nominal no contribuye a la recuperación del material elidido no implica que sea indiferente que en el resto de un SN con núcleo elíptico aparezcan o no marcas flexivas, en particular, marcas de número. Al igual que las expresiones nominales plenas, una expresión nominal con elipsis debe contener información (léxica o morfológica) que especifique si su referencia es singular o plural, ya que esta distinción resulta crucial a la hora de identificar la entidad o entidades de que se trata y facilitar, de este modo, que dicha expresión nominal pueda funcionar como argumento de un predicado (cf. Bouchard 2002). Así se podría explicar, por ejemplo, la agramaticalidad de los SSNN elípticos introducidos por el artículo determinado en inglés (24b) o por el determinante interrogativo qué en nuestra lengua $(25 \mathrm{~b})$ :

(24) a. Los estudiantes de París y los $[\mathrm{v}]_{\mathrm{N}}$ de Madrid.

b. The students from Paris and the *(ones) from Madrid.

(25) a. Yo he visto dos películas . ¿Cuántas [v] has visto tú?

b. Yo he visitado estas ciudades. ${ }^{*}$ ¿ué $[\mathrm{v}]_{\mathrm{N}}$ has visitado tú?

A diferencia del artículo determinado del español y del interrogativo cuánto, el artículo determinado del inglés y el interrogativo qué no están flexionados. Como hemos visto, el hecho de que estos determinantes sean invariables no impide que el contenido descriptivo de la clase denotada por el nombre elidido pueda ser recuperado. De hecho, tanto el artículo determinado como el determinante interrogativo qué vinculan la expresión nominal que introducen con el discurso y, en principio, favorecen la elipsis (cf. §5). El problema no es este. El problema está en que los SSNN con núcleo vacío introducidos por el artículo determinado del inglés o por el interrogativo qué del español no contienen información alguna sobre el número singular o plural de su referente y no pueden ser, por tanto, argumentos de un predicado. De ahí que estén mal formados.

Las marcas de número, en conclusión, no identifican formalmente una categoría nominal vacía. Su aparición en los SSNN con elipsis no guarda relación con la recuperación del contenido descriptivo elidido.

de género y de número nos enseña es que una y otra son de distinta naturaleza. La elipsis nominal debe producirse bajo condiciones de identidad estricta entre el nombre elidido y su antecedente. El que no pueda haber discordancia de género entre ambos muestra, por tanto, que el género es un rasgo léxico, una propiedad inherente de los nombres. El número, en cambio, es un rasgo sintáctico, una propiedad de todo el SN. Si se tiene en cuenta que la condición de identidad estricta afecta solo al material elidido y no al sN en su conjunto, puede entonces ocurrir que no coincidan el número del sustantivo elidido y el de su antecedente. El dispar comportamiento de la morfología de género y de número en la elipsis nominal ha sido puesto de manifiesto por distintos autores: cf., p. ej., Brucart 1987b, 1999, Contreras 1992, Kornfeld y Saab 2004, Leonetti 1999, Masullo y Depiante 2003, Ronat 1977 y Saab 2004. 
Estas marcas denotan simplemente la naturaleza singular o plural del SN con elipsis y permiten así que pueda actuar como argumento de un predicado.

Hasta el momento he presentado evidencias de distinto tipo que ponen en entredicho los dos supuestos centrales de los análisis formales de la elipsis nominal en español (cf. § II). Por un lado, los casos de nombres escuetos continuos y discontinuos en plural con elipsis, una vez descartado que exista un cuantificador vacío en estas construcciones, muestran que es posible elidir el núcleo nominal en ssNN sin determinante y son, por tanto, un contraejemplo para la condición de legitimación del sustantivo elidido a través de una relación estructural de rección. Estos mismos datos, así como los ejemplos de elipsis nominal en ssNN introducidos por determinantes invariables, indican, por otro lado, que la presencia de marcas flexivas en el resto no es necesaria para que pueda producirse la elipsis nominal y son un claro contraejemplo, a su vez, para la condición formal de identificación de los nominales vacíos por medio de rasgos flexivos de concordancia. Han de ser otras, en conclusión, las condiciones que regulan la formación de ssNn con núcleo tácito en nuestra lengua. Como se verá en los dos siguientes apartados, estas condiciones son de naturaleza semántica.

\section{LA NATURALEZA DEL DETERMinANTE}

Se ha apuntado ya antes en varias ocasiones que, con independencia de que estén flexionados o sean invariables, no todos los determinantes del español acompañan a un nominal vacío:

(26) a. \{Muchas/Dos\} (hipótesis) son falsas.

b. $\{$ Toda/Cada $\} *$ (hipótesis) tiene un contraejemplo.

En esta sección intentaré explicar por qué hay en nuestra lengua determinantes que son compatibles con la elipsis nominal, mientras que otros la rechazan.

\subsection{Construcciones partitivas y expresiones nominales elípticas}

Una diferencia significativa entre determinantes como muchos o dos y determinantes como todo o cada es que solo los primeros pueden ser la cabeza de una construcción partitiva ${ }^{19}$ :

(27) a. $\{$ Muchos/Dos\} de los libros de Cela.

b. $*\{$ Cada/Todo $\}$ de los libros de Cela.

\footnotetext{
${ }^{19}$ Contreras 1989, 1992 da una explicación estructural del contraste de (26). Por razones de espacio no discutiré aquí la propuesta de este lingüista, que no comparto.
} 
Si se toma este contraste como punto de partida y se comparan las construcciones partitivas y las expresiones nominales con elipsis, se descubre una primera generalización sobre las relaciones entre los determinantes y la elipsis nominal en español (y en otras lenguas). Como se ilustra en (28) y (29), todos los determinantes que encabezan una construcción partitiva introducen también SSNN con núcleo vacío:

(28) a. \{Una/Otra/Ninguna/Cualquiera\} de las películas de Garci.

b. \{Algunos/Muchos/Bastantes/Varios\} de los libros de Cela.

(29) a. \{Una/Otra/Ninguna/Cualquiera $\left.]_{\mathrm{v}}\right]_{\mathrm{N}}$ (de Garci) me gusta mucho.

b. He leído \{algunos/muchos/bastantes/varios\} $[\mathrm{v}]_{\mathrm{N}}$ (de Cela).

La pregunta que tenemos que plantearnos, claro está, es por qué se da este paralelismo entre construcciones partitivas y ssNn con elipsis. Y la respuesta parece tener que ver con la semántica, en parte coincidente, de ambas construcciones. Una construcción partitiva está introducida canónicamente por un determinante indefinido (la cabeza) que escoge un subconjunto dentro un conjunto definido (la coda). En esta relación entre un subconjunto y un conjunto de entidades de la misma clase, basta con expresar una sola vez la clase de que se trata: en concreto, como la clase está expresada en la coda, no hace falta mencionarla de nuevo en la cabeza de la partitiva. El contenido de la clase a la que hace referencia implícitamente el indefinido se recupera, por tanto, a partir de lo expresado en la coda.

Algo semejante ocurre en los casos de elipsis nominal con estos indefinidos. Los indefinidos que encabezan una construcción partitiva tienen también, cuando se combinan con un sustantivo elidido, una interpretación inherentemente partitiva, que nos indica que estamos ante un subconjunto que ha sido extraído de un conjunto mayor de elementos de la misma clase ${ }^{20}$. Como sabemos, la elipsis nominal solo es posible si el contenido del sustantivo elidido puede ser recuperado a partir de información contextual. Pues bien, el determinante indefinido nos da una pista que nos permite recuperar esta información: habida cuenta de que la interpretación partitiva del indefinido presupone necesariamente la existencia de un conjunto de individuos de la misma clase, no es necesario mencionar de nuevo la clase en cuestión si se dispone de esta información en el contexto.

Ahora bien, quedan problemas por resolver. La relación entre los determinantes y la elipsis nominal es bastante más compleja. Acabamos de ver que todos los determinantes que encabezan una construcción partitiva se combinan, además, con un sustantivo elidido. Hay, sin embargo, determinantes que no encabezan una construcción partitiva que permiten la elipsis nominal $(30,31)$ y otros que no la permiten (32, 33):

\footnotetext{
${ }^{20}$ La naturaleza partitiva de los determinantes indefinidos en las construcciones con elipsis se manifiesta claramente en lenguas románicas próximas a la nuestra con la aparición del clítico partitivo en/ne: cat. en veig tres, fr. j'ai en vu trois, it. ne vedo tre.
} 
(30) a. *\{Más/Menos $\}$ de los estudiantes de primero han suspendido el examen.

b. *\{Todas/Estas/Otras $\}$ de las preguntas.

(31) a. Han suspendido \{más/menos\} [v] que el año pasado.

b. \{Todas/Estas/Otras\} [v] son interesantes.

(32) a. *\{Cada/Todo) de los animales.

b. $*\{$ Distintos/Ciertos $\}$ de los políticos.

(33) a. * $\{\mathrm{Cada} / \mathrm{Todo}\}[\mathrm{v}]$ se adapta a su medio.

b. $*\{$ Distintos/Ciertos $\}[\mathrm{v}]$ votaron en contra.

En la bibliografía sobre la elipsis nominal se pueden encontrar dos propuestas que nos pueden ayudar a arrojar luz sobre esta cuestión.

\subsection{El concepto de «partitividad ampliada» o «vinculación discursiva»}

Sleeman 1996 sostiene que la partitividad no es una propiedad semántica exclusiva de las construcciones partitivas y defiende la idea de que también puede calificarse como partitiva cualquier otra relación que indique que existe un conjunto en el dominio del discurso del cual el sN con el nominal vacío es un subconjunto. Además, la noción de partitividad cubre, en su opinión, tanto el concepto de «inclusión propia» como el de «inclusión impropia»: la inclusión propia denota la inclusión de un subconjunto, definido o indefinido, en un conjunto de referencia; una relación de inclusión impropia es, a su vez, aquella en la que un conjunto es idéntico al conjunto de referencia. Haciendo uso de este concepto de partitividad (ampliada), propone Sleeman que la elipsis nominal implica siempre una relación de inclusión de un (sub) conjunto en un conjunto conocido que permite que el contenido elidido pueda ser recuperado ${ }^{21}$.

López 2000 adopta, por su parte, el concepto de «vinculación discursiva» (D-linking) de Pesetsky 1987 para dar cuenta de los casos en que puede producirse la elipsis nominal. Pesetsky utiliza este término para referirse a la capacidad que tienen una parte de los pronombres y los determinantes interrogativos de escoger una entidad o un conjunto de entidades de entre un conjunto de alternativas que son accesibles en el contexto lingüístico o extralingüístico tanto para el hablante como para el oyente. Un hablante, por poner un ejemplo, solo emplearía una

\footnotetext{
${ }^{21}$ Véase también Bouchard 2002 y Martinho 1998. Lobeck 1995 afirma que existe un rasgo (formal) de concordancia «fuerte» [+partitivo], junto a los rasgos [+plural] y [+posesivo], que permite la identificación del nominal elidido en inglés. Sleeman 1993, 1996 propone, en cambio, que la partitividad es una propiedad semántica y engloba bajo este concepto los tres rasgos propuestos por Lobeck. Esta lingüista explica, por tanto, todos los casos en los que aparecen sustantivos elididos por medio de un solo principio: un sustantivo elidido debe estar legitimado formalmente por una unidad léxica rectora con significado partitivo. Nótese que en este principio, tal y como está formulado, se mantiene uno de los postulados básicos de los análisis formales de la elipsis nominal: la idea de que los nominales vacíos deben estar regidos (véanse a este respecto los comentarios de la nota siguiente).
} 
oración interrogativa como ¿Cuál prefieres? si tanto el hablante como el oyente saben qué conjunto de entidades sirve como punto de referencia para que lleve a cabo su elección el oyente. Inspirándose en esta idea, y habida cuenta de que la elipsis nominal consiste en omitir material cuyo contenido debe ser recuperado a partir de información aportada por el contexto, sostiene López que esta operación solo es posible si el SN elíptico está vinculado con un tópico discursivo ${ }^{22}$. Como reconoce este autor (cf. López 2000, p. 193, nota 11), la idea de que los SSNN con elipsis deben estar vinculados con el discurso coincide básicamente con la propuesta de Sleeman de que dichos SSNN son subconjuntos de SSNN mencionados previamente. En lo que sigue haré uso de manera indistinta, por tanto, bien de la noción de partitividad (ampliada), bien del concepto de vinculación discursiva con el fin de dar cuenta del hecho de que haya determinantes que no encabezan una construcción partitiva que admiten la elipsis nominal y otros que no lo hacen. Veamos algunos casos significativos.

El primero de ellos tiene que ver con el distinto comportamiento de los cuantificadores universales todos y todo en las construcciones con elipsis nominal. Como se observa en (34), ninguno de estos dos cuantificadores encabeza una construcción partitiva, pero todos introduce un SN elíptico:

(34) a. *\{Todos/Todo $\}$ de los alumnos respetan al profesor.

b. $\{$ Todos $/ *$ Todo $\}$ respeta(n) al profesor.

Tanto el concepto de partitividad ampliada como el de vinculación discursiva nos ayudan a aclarar el contraste de (34b). Enç 1991 sostiene que un cuantificador universal como todos cuantifica sobre conjuntos contextualmente relevantes, esto es, sobre conjuntos que están presentes en el dominio del discurso. Dicho de otro modo, el rango de un SN cuantificado por todos está restringido por el contexto. La oración, por ejemplo, todos los estudiantes suspendieron el examen no significa que todos los estudiantes del mundo suspendieran el examen en cuestión, sino que se refiere al conjunto de estudiantes que es relevante para el hablante y el oyente en el momento del habla. El cuantificador universal todo, en cambio, tiene un dominio irrestricto (su rango está formado por todos los miembros posibles de la clase en cuestión). Por lo tanto, solo

\footnotetext{
${ }^{22}$ Propone López, en concreto, que la elipsis nominal está legitimada por una categoría funcional que tiene la propiedad de establecer una conexión con un tópico discursivo. Este lingüista, al igual que Sleeman 1996 (véase la nota anterior), no se aparta, por tanto, del todo de los análisis formales de la elipsis nominal (cf. § II). Sin embargo, el requisito de que una categoría nominal vacía deba estar regida por una categoría funcional no se cumple, como veíamos, en los casos de elipsis nominal con nombres escuetos (cf. § III). Además, el que un SN esté vinculado con un tópico discursivo (o tenga interpretación partitiva) parece ser una propiedad de todo el SN y no solo del determinante (véanse a este respecto los datos de elipsis nominal con adjetivos de $§$ VI). Por ello, la vinculación discursiva (o la partitividad) se tratarán aquí como meras condiciones semánticas.
} 
todos establece una relación de inclusión (impropia) con un conjunto contextualmente accesible o, dicho en otros términos, solo todos vincula la expresión nominal que introduce con un tópico discursivo y puede aparecer en expresiones nominales con elipsis.

Los comparativos más y menos tampoco encabezan una construcción partitiva $^{23}$, pero permiten que se produzca la elipsis del núcleo nominal:

(35) a. *\{Más/Menos\} de los estudiantes de primero han suspendido.

b. Han suspendido $\{$ más/menos $\}[\mathrm{v}]_{\mathrm{N}}$ que el año pasado.

Este hecho se puede explicar si tomamos en consideración que la comparación implica la existencia de un conjunto de referencia en el dominio del discurso, de manera que no es necesario expresar de nuevo el sustantivo para denotar la clase en cuestión. La comparación es, por tanto, un mecanismo de vinculación discursiva que habilita la elipsis nominal.

$\mathrm{Al}$ igual que los comparativos más y menos, los demostrativos no encabezan una construcción partitiva ${ }^{24}$, pero son perfectamente compatibles con un sustantivo elidido:

(36) a. *Estas de las preguntas son interesantes.

b. Estas $[\mathrm{v}]_{\mathrm{N}}$ son interesantes.

Autores como Sleeman 1996 o Martinho 1998 recurren al concepto de partitividad ampliada para dar cuenta de este hecho. Piensan estos lingüistas, en concreto, que los demostrativos, aun siendo definidos, pueden quedar incluidos entre los elementos partitivos porque denotan subconjuntos de un conjunto de referencia. Se podría decir, igualmente, que dada su naturaleza deíctica, los demostrativos vinculan el sN elíptico que los contiene con el discurso, esto es, presuponen la existencia de un conjunto de referencia en el contexto lingüistico o extralingüístico.

Esta línea de razonamiento se puede aplicar también al caso del indefinido plural otros. Como se observa en (37), el plural otros, frente al singular otro, no puede ser la cabeza de una construcción partitiva, probablemente porque carece de valor cuantitativo. Este mismo contraste se da también entre el singular un y el plural unos. Sin embargo, aun no pudiendo encabezar una partitiva, el plural otros, al igual que el singular otro, admite la elipsis nominal ${ }^{25}$ :

${ }^{23}$ Probablemente este hecho se deba a que son inherentemente inespecíficos, mientras que la posición de cabeza de una partitiva está asociada habitualmente con la interpretación específica de los indefinidos (cf. Enç 1991).

${ }^{24}$ Como es sabido, los demostrativos no pueden ser la cabeza de una partitiva porque son definidos y estas construcciones están encabezadas, canónicamente, por determinantes indefinidos (que no denotan la totalidad de los miembros de la clase en cuestión).

${ }^{25}$ Sobre el indefinido de contraste otro(s) véase Eguren y Sánchez 2003, 2004. Acerca de las propiedades particulares del indefinido plural unos véase Gutiérrez Rexach 2001. 
(37) a. $\{$ Una/Otra $/ *$ Unas $/ *$ Otras $\}$ de las preguntas.

b. $\{$ Otra/Otras $\}[\mathrm{v}]_{\mathrm{N}}\{$ resultó/resultaron $\}$ interesante $(\mathrm{s})$.

Desde la perspectiva que estoy adoptando no es difícil explicar este hecho: otros, al igual que el singular otro, es un «indefinido de contraste», que identifica un miembro distinto de una clase ya conocida. Esta relación de contraste entre dos elementos de una misma clase hace innecesario que la clase sea expresada de nuevo en el SN introducido por otro(s).

La comparación, la deixis y el contraste pueden muy bien concebirse, en suma, como mecanismos específicos que facilitan la vinculación de una expresión nominal con un tópico discursivo y hacen posible, de este modo, que pueda elidirse el núcleo nominal.

La ausencia de algún rasgo, como los mencionados, que permita anclar discursivamente el $\mathrm{SN}$ elíptico es lo que podría explicar, en mi opinión, que los determinantes indefinidos cierto(s), unos, determinados o numerosos $^{26}$, que no encabezan una construcción partitiva (38), tampoco se combinen con un nominal vacío (39):

(38) a. *\{Unos/Ciertos\} de los políticos españoles acudieron a la manifestación.

b. *\{Determinadas/Numerosas\} de las propuestas fueron interesantes.

(39) a. *\{Unos/Ciertos $\}[\mathrm{v}]_{\mathrm{N}}$ acudieron a la manifestación.

b. $*\{$ Determinadas/Numerosas $\}[\mathrm{v}]_{\mathrm{N}}$ fueron interesantes.

Todo parece indicar, por tanto, que de la clase de los determinantes indefinidos solo legitiman la elipsis nominal los indefinidos que encabezan una partitiva ${ }^{27}$ y aquellos que, aun no haciéndolo, tienen alguna propiedad semántica que permite vincular el SN que introducen con el discurso (como los comparativos o el indefinido de contraste plural otros, por ejemplo).

El caso del indefinido plural distintos es especialmente ilustrativo a este respecto. Al igual que unos, otros, cierto(s) y determinados, distintos ni encabeza una construcción partitiva, ni legitima nominales vacíos:

(40) a. *Distintas de las propuestas fueron rechazadas.

b. $*$ Distintas $[\mathrm{v}]_{\mathrm{N}}$ fueron rechazadas.

Lo interesante del caso del indefinido distintos es que este determinante no solo no posee ningún rasgo que vincule el sN que introduce con un tópico discursivo, sino que sus propiedades semánticas bloquean incluso la relación de vinculación discursiva. Nótese a este respecto que, mientras que el distintos adjetival que aparece en posición posnominal admite tanto una lectura recíproca o interna al sN, como una lectura

\footnotetext{
${ }^{26}$ Sobre la gramática de cierto véase Eguren y Sánchez 2007a,b.

${ }^{27}$ Una prueba de que esto es así es que, en comparación con el cierto del español, el indefinido certain(es) encabeza una partitiva y permite también la elipsis nominal en francés: Certaines des maisons ont été démolies, Parmi les maisons, certaines $[v]_{N}$ ont été démolies.
} 
anafórica o externa al SN (41a), el determinante distintos solo admite la lectura interna al sN y excluye la interpretación anafórica $(41 \mathrm{~b})^{28}$ :

(41) a. Mis alumnos han leído libros distintos.

'Los libros que han leído mis alumnos son distintos unos de otros'

'Los libros que han leído mis alumnos son distintos de otros conocidos'

b. Mis alumnos han leído distintos libros.

'Los libros que han leído mis alumnos son distintos unos de otros'

*'Los libros que han leído mis alumnos son distintos de otros conocidos'

La naturaleza no anafórica del determinante indefinido distintos es lo que impide, por tanto, que el sintagma nominal que introduce esté vinculado con el discurso. De ahí que el sustantivo no pueda omitirse.

De lo dicho en este apartado se pueden extraer, básicamente, dos conclusiones: (a) Solo los determinantes que tengan alguna propiedad semántica que los habilita para vincular el sN que los contiene con un tópico discursivo admiten la elipsis nominal ${ }^{29}$, y (b) existen mecanismos específicos que hacen posible que un SN con núcleo elidido esté vinculado con el discurso: entre ellos, la identificación deíctica, las relaciones de comparación o contraste y el hecho de que el determinante sea «léxicamente» partitivo (esto es, encabece una construcción partitiva).

\section{MODIFICACIÓN ADJETIVAL Y ELIPSIS NOMINAL}

Como sabemos, para las teorías semánticas de la elipsis nominal, la buena formación de los sintagmas nominales con núcleo tácito depende del cumplimiento de dos condiciones que se complementan. La prime ra de ellas es que el sintagma nominal con núcleo elidido ha de estar

\footnotetext{
${ }^{28}$ Sobre las propiedades de las piezas léxicas equivalentes al indefinido distintos en alemán, inglés y francés véase Beck 2000 y Laca y Tasmowski 2004.

${ }^{29}$ Quedan algunos casos que merecen un comentario aparte. El determinante interrogativo quévincula el SN que introduce con el discurso, pero no legitima un nominal vacío, quizás porque carece de marcas de número, lo cual es imprescindible para que un sN con núcleo vacío pueda funcionar como argumento (cf. § IV). Los determinantes sendos, tal(es), semejante(s), tamaño(s) y dichos(s) tampoco admiten la elipsis nominal. La causa de esta incompatibilidad tal vez resida, en este caso, en que su carácter exclusivamente anafórico les impide poder escoger un alternativa dentro de un conjunto de alternativas de modo que no pueden ser interpretados como foco contrastivo (véase el apartado II). Un caso distinto es el del artículo determinado y los posesivos. El artículo determinado y los posesivos son determinantes definidos y vinculan, por tanto, la expresión nominal que los contiene con el discurso y deberían, en consonancia con lo dicho en esta sección, legitimar sustantivos vacíos. Sin embargo, como se sabe, el artículo determinado tiene una distribución restringida en los ssNN con elipsis y los posesivos prenominales son totalmente incompatibles con un núcleo nominal elidido. A falta de una explicación alternativa más convincente, se podría atribuir el peculiar comportamiento de estas piezas léxicas en las expresiones nominales con elipsis a su naturaleza átona: se trataría de «clíticos léxicos», que escogen los elementos a los que se adjuntan (véase a este respecto Eguren 2008, y las referencias allí citadas).
} 
vinculado con un tópico discursivo. La segunda es que el resto debe recibir una interpretación de foco contrastivo. Acabamos de ver cómo depende de estas restricciones la naturaleza de los determinantes que se combinan con un sustantivo elidido. En esta sección se comprobará que estas dos condiciones semánticas nos permiten explicar, además, en qué casos se produce la elipsis en sintagmas nominales cuyo núcleo vacío está modificado por un adjetivo.

\subsection{Adjetivos determinativos}

Llamaré «adjetivos determinativos» a aquellos que denotan una cantidad o contribuyen al establecimiento de la referencia del sN del que forman parte. Pertenecen a esta clase los adjetivos prenominales mismo, demás y único, así como los numerales cardinales y los determinativos $\mathrm{mu}$ cho/poco, otro y distintos cuando están precedidos por un determinante:

(42) a. Los \{mismos/demás/únicos\} supervivientes abandonaron la isla.

b. Los $\{$ dos/muchos/otros/distintos $\}$ proyectos que han presentado.

El comportamiento de los miembros de esta clase de adjetivos en expresiones nominales con elipsis corrobora la idea de que un sintagma nominal con núcleo elidido debe estar vinculado con un tópico discursivo. Como se ilustra en (43), en el caso de los numerales cardinales adjetivales y de los adjetivos determinativos mucho, otro y distintos se reproducen exactamente los contrastes que se observan cuando estas piezas léxicas funcionan como determinantes (véase el apartado anterior):

(43) a. He leído todos los libros de Cortázar y los dos $[\mathrm{v}]_{\mathrm{N}}$ de Rulfo.

b. Las pocas preguntas a las que respondió no fueron precisamente las más interesantes de las muchas $[\mathrm{v}]_{\mathrm{N}}$ que se le hicieron.

c. A Juan le gusta este traje, pero Antonio prefiere el otro $[\mathrm{v}]_{\mathrm{N}}$.

d. *La única idea de María al respecto es mucho mejor que las distintas $[\mathrm{v}]_{\mathrm{N}}$ que se le han ocurrido a Ana.

Cuando les precede un determinante que está vinculado con el discurso, los numerales cardinales y los numerales imprecisos muchos y pocos, que tienen un significado partitivo, no interfieren en la relación que dicho determinante establece entre el SN que introduce y el discurso (43a, b). Como sugiere la buena formación del ejemplo de (43c), el determinativo de contraste otro no solo no obstaculiza esta relación, sino que la refuerza (recuérdese que el contraste es una de las expresiones de la relación de vinculación discursiva). El adjetivo determinativo distintos, en cambio, bloquea la relación de vinculación discursiva que el determinante establece, ya que, como hace el determinante distintos, impone una interpretación recíproca, interna al sN: de ahí la agramaticalidad de la oración de (43d). 
Los adjetivos determinativos mismo, demás y único tienen, a su vez, propiedades semánticas propias que hacen que sean compatibles con la elipsis nominal:

(44) a. Vimos varios coches. Al final Juan se compró el mismo [v] que yo.

b. Fueron a la huelga pocos maestros. Los demás $[\mathrm{v}]_{\mathrm{N}}$ trabajaron.

c. Hicimos el examen tres estudiantes. El único $[\mathrm{v}]_{\mathrm{N}}$ que aprobó fui yo.

El mismo identificativo indica que dos o más miembros de una clase de entidades son idénticos y esta relación de identidad hace innecesario que la clase tenga que expresarse de nuevo en el SN introducido por el determinativo (la identidad, como el contraste, es uno de los mecanismos de vinculación discursiva que permite la recuperación del contenido de un sustantivo elidido). El adjetivo determinativo demás, que denota el resto de los miembros de un conjunto, extrae una parte de dicho conjunto y este significado partitivo le permite ser compatible con la elipsis nominal. El determinativo único, finalmente, tiene valor cuantitativo e incluso puede ser, combinado con el artículo determinado, la cabeza de una construcción partitiva (Juan es el único de mis alumnos que está en contra). Este adjetivo determinativo aparece, por tanto, sin problemas en SSNN con núcleo vacío.

\subsection{Adjetivos restrictivos y adjetivos no restrictivos}

Como se sabe, los adjetivos que denotan propiedades pueden ser restrictivos o no restrictivos. Son adjetivos restrictivos los adjetivos calificativos posnominales y los adjetivos relacionales. Los primeros denotan una propiedad del sustantivo al que modifican y limitan su extensión. Los segundos establecen un vínculo entre lo denotado por el sustantivo al que modifican y algún otro nombre y restringen igualmente su extensión. Ambas clases de adjetivos restrictivos tienen, por tanto, significado partitivo, esto es, seleccionan un subconjunto de la clase denotada por el nombre. Este significado partitivo es, como ya se ha dicho en varias ocasiones, compatible con la elipsis nominal. De ahí que los sintagmas nominales con núcleo vacío y modificadores adjetivales de esta clase estén bien formados. Los ejemplos de (45) incluyen ssNN elípticos con adjetivos calificativos posnominales

(45) a. Se viaja más cómodo en los trenes rápidos que en los $[\mathrm{v}]_{\mathrm{N}}$ lentos.

b. Las novelas divertidas se venden mejor que las $[\mathrm{v}]_{\mathrm{N}}$ aburridas.

y en (46) se ofrecen datos del mismo tipo de las dos subclases de adjetivos relacionales, los adjetivos argumentales o temáticos -cf (46a)-, y los adjetivos clasificadores -cf. (46b)-:

(46) a. La decisión alemana fue más prudente que la $[\mathrm{v}]_{\mathrm{N}}$ italiana. 
b. La energía atómica es mucho más peligrosa que la $[\mathrm{v}]_{\mathrm{N}}$ solar.

A diferencia de lo que ocurre en el caso de los adjetivos restrictivos (calificativos y relacionales), la presencia de un adjetivo calificativo prenominal impide, tal y como se muestra en los ejemplos de (47), que el SN que lo contiene pueda estar encabezado por un sustantivo tácito ${ }^{30}$ :

(47) a. *Se viaja más cómodo en estos rápidos trenes que en esos lentos $[\mathrm{v}]_{\mathrm{N}}$.

b. *Aquellas divertidas novelas se vendían mejor que estas aburridas $[\mathrm{v}]_{\mathrm{N}}$.

Ha de existir, por tanto, algún tipo de incompatibilidad entre la semántica de esta clase de adjetivos y el requisito de que los SsNN con elipsis deban estar vinculados con el discurso. Los adjetivos calificativos prenominales destacan un rasgo del objeto denotado por la entidad de la que se predican. Al contrario que los adjetivos restrictivos, su aparición no limita, por tanto, la extensión de la clase a la que se aplica. Pues bien, el hecho de que los adjetivos calificativos prenominales sean no restrictivos (o no partitivos) es precisamente lo que impide que el sN elíptico pueda estar vinculado con el discurso ${ }^{31}$.

\subsection{Adjetivos distintivos y adjetivos no distintivos}

Que el adjetivo sea restrictivo o no restrictivo no es el único factor que incide en la buena formación de las expresiones nominales con núcleo elidido y modificadores adjetivales. Como han señalado distintos autores $^{32}$, también resulta relevante en estos casos la partición de la clase de los adjetivos calificativos restrictivos en «adjetivos distintivos o discriminativos» $y$ «adjetivos no distintivos o no discriminativos».

Los adjetivos distintivos denotan cualidades discriminativas fácilmente reconocibles, como el color o las propiedades expresadas en contrastes binarios paradigmáticos como grande/pequeño, largo/corto, viejo/nuevo, etc. Estos adjetivos sirven para crear subconjuntos y su uso se asocia de manera natural a un conjunto de referencia. Los adjetivos no distintivos, por su parte, denotan propiedades más subjetivas y abs-

\footnotetext{
${ }^{30}$ Este hecho ha sido observado por distintos autores: cf., p. ej., Bernstein 1993, Contreras 1992, Demonte 1999, Leonetti 1999, Llombart-Huesca 2002 y Ronat 1977.

${ }^{31}$ Autores como Contreras 1992, Demonte 1999 y Sleeman 1993 proponen una explicación formal para este fenómeno y sugieren que la presencia de ciertos adjetivos prenominales constituye una «barrera» para la rección que impide que el nominal vacío quede legitimado. No discutiré aquí estas propuestas. Nótese, en cualquier caso, que tal y como señala acertadamente Bouchard 2002, p. 267, nota 4, el supuesto bloqueo estructural por parte de los adjetivos calificativos prenominales de la relación de rección entre un determinante y el sustantivo elidido es redundante con la incompatibilidad semántica entre el significado no partitivo del adjetivo y el significado vinculado al discurso del determinante.

${ }^{32}$ Véase, p. ej., Bouchard 2002, Jones 1993, Martinho 1998 y Sleeman 1993, 1996.
} 
tractas, no tan claramente discriminativas. Dichos adjetivos definen también subconjuntos, pero tales subconjuntos no son lo suficientemente reconocibles en términos cognitivos como para poder ser asociados de manera inequívoca a un conjunto de referencia (por poner un ejemplo, mientras que solo determinadas entidades tienen la propiedad de ser verdes, en principio y dependiendo del punto de vista, cualquier entidad puede ser interesante). Así las cosas, en palabras de Jones 1993, pp. 73-74), "para poder modificar a un sustantivo sin realización fonética, el adjetivo debe denotar una propiedad lo bastante concreta como para que el interlocutor pueda reconocerla fácilmente como una propiedad que distingue al referente en cuestión frente a otros referentes potenciales». La distinción entre adjetivos distintivos y no distintivos está en la base, por ejemplo, de contrastes como los siguientes ${ }^{33}$ :

(48) a. Prefiero el $[\mathrm{v}]_{\mathrm{N}}$ verde.

b. Coge la $[\mathrm{v}]_{\mathrm{N}}$ grande.

c. \#No escuché la $[\mathrm{v}]_{\mathrm{N}}$ interesante.

d. \#Resolví el $[\mathrm{v}]_{\mathrm{N}}$ fácil.

Todos los adjetivos de los ejemplos de (48) son adjetivos calificativos restrictivos que seleccionan un subconjunto de un conjunto de referencia y, a tenor de lo dicho en el subapartado anterior, deberían ser compatibles con la elipsis nominal. Sin embargo, los adjetivos distintivos (verde, grande) admiten la omisión del núcleo nominal en un contexto empobrecido con mucha más facilidad que los adjetivos no distintivos (interesante, fácil). Ahora bien, tal y como indica el símbolo que los precede, los ejemplos de (48c,d) son pragmáticamente anómalos, pero no agramaticales. Prueba de ello es que estos enunciados pueden proferirse en contextos contrastivos discriminativos, en los que los adjetivos inherentemente no distintivos adquieren ahora valor distintivo y denotan un subconjunto de un conjunto de referencia fácilmente accesible:

(49) a. Me perdí la conferencia aburrida y la $[\mathrm{v}]_{\mathrm{N}}$ interesante.

b. El problema difícil y el $[\mathrm{v}]_{\mathrm{N}}$ fácil están en la página cuarenta.

La presencia de un adjetivo restrictivo no distintivo en un SN con núcleo tácito no tiene, en conclusión, el mismo efecto que la de un adjetivo no restrictivo. Estos, debido a su naturaleza no partitiva, son incompatibles con la elipsis nominal sea cuál sea el contexto en el que aparece el SN elíptico. La combinación de un adjetivo no distintivo y un sustantivo tácito resulta, en cambio, aceptable en contextos contrastivos en los que el adjetivo adquiere valor distintivo y contribuye así a fijar de manera inequívoca el referente del SN con núcleo vacío ${ }^{34}$. Este fenómeno debe entenderse, en mi opinión, como una de las manifestaciones

\footnotetext{
${ }^{33}$ Parecidos contrastes se observan también en francés: véase Sleeman 1993, 1996.

${ }^{34}$ Este mismo paradigma se obtiene también en el caso de los adjetivos calificativos elativos posnominales, que tienen un contenido valorativo enfático que les impide fijar inequívocamente la referencia del SN con núcleo elidido.
} 
de la incidencia que en la buena formación de los SSNN con elipsis tiene la condición de que el resto deba recibir una interpretación de foco contrastivo (cf. § II).

\subsection{Adjetivos adverbiales}

Los adjetivos adverbiales reciben este nombre, como se sabe, porque su significado es similar al de de los adverbios en -mente correspondientes que modifican a los predicados oracionales. Estos adjetivos suelen ser prenominales y se distinguen de los calificativos en que no denotan clases, es decir, en que no asignan propiedades a los nombres con que se combinan: existe, por ejemplo, la clase de las cosas rojas o de las cosas redondas, pero no existe la clase de las entidades posibles, meras o siguientes.

Los sintagmas nominales con núcleo elidido no admiten fácilmente, por lo general, modificadores adjetivales adverbiales. Algunos de estos adjetivos, combinados con un sustantivo tácito, dan lugar a secuencias pragmáticamente anómalas (50), mientras que otros son totalmente incompatibles con la elipsis nominal (51):

(50) a. \#El juez condenó al presunto $[\mathrm{v}]_{\mathrm{N}}$.

b. \#El rey no saludó al antiguo $[\mathrm{v}]_{\mathrm{N}}$.

(51) a. *La original respuesta del conferenciante no fue una simple $[\mathrm{v}]_{\mathrm{N}} \sin$ más.

b. *Antonio dijo una supuesta verdad y Pedro le contestó con la pura $[\mathrm{v}]_{\mathrm{N}}$.

Una manera plausible de explicar el paradigma de (50)-(51) es extender a este caso las reflexiones que en el subapartado anterior se hacían en torno a la distinción entre adjetivos distintivos y adjetivos no distintivos y al papel que desempeña en la buena formación de los SSNN con elipsis la condición de que el resto deba recibir una interpretación contrastiva. Todos los adjetivos adverbiales de (50) y (51) son no distintivos (denotan nociones abstractas no discriminativas), pero algunos de ellos forman parte de pares de adjetivos con significados opuestos: verdadero/presunto, futuro/antiguo. Estos adjetivos adverbiales, en particular, cuando aparecen en contextos contrastivos discriminativos, adquieren valor distintivo y pueden, por tanto, modificar a un sustantivo elidido:

(52) a. El juez se equivocó y condenó al verdadero asesino y al presunto $[\mathrm{v}]_{\mathrm{N}}$.

b. El rey no saludó ni al actual presidente ni al antiguo $[\mathrm{v}]_{\mathrm{N}}$.

En cambio, adjetivos adverbiales como simple o puro no forman parte de pares de adjetivos con significados opuestos. En consecuencia, nunca admiten la elipsis nominal, ya que su presencia infringe la condición de que el resto deba tener una interpretación contrastiva. 
Comentario aparte merecen, y con ello doy por cerrada esta sección, adjetivos adverbiales circunstanciales como siguiente, precedente, anterior, posterior, próximo o pasado, que denotan relaciones de precedencia o sucesión en una secuencia temporal o espacial de elementos de una misma clase de entidades. Esta relación «serial» hace innecesario que la clase en cuestión sea expresada de nuevo en el sN que contiene uno de estos adjetivos. O dicho de otro modo, la seriación es un mecanismo de vinculación discursiva, como la deixis, la comparación o el contraste (cf. $\S 5.2$ ), que facilita la recuperación del contenido del sustantivo elidido. Tal y como se ilustra en (53), los adjetivos circunstanciales seriales son, en consonancia con este hecho, plenamente compatibles con la elipsis nominal:

(53) a. Yo me bajo en la próxima $[\mathrm{v}]_{\mathrm{N}} \cdot \mathrm{C} Y$ usted?

b. Alonso ganó las dos primeras carreras. La siguiente $[\mathrm{v}]_{\mathrm{N}}$ la perdió.

En Eguren y Fábregas 2005 se afirma, por ende, que los adjetivos ordinales prenominales pertenecen a la clase de los adjetivos circunstanciales como siguiente, anterior o pasado ${ }^{35}$. Los ordinales prenominales, en tanto que adjetivos seriales, son inherentemente relacionales, pero se distinguen de estos en que convierten un conjunto en una serie ordenada. Los ordinales prenominales presuponen, por tanto, la existencia en el dominio del discurso de un conjunto del que extraen determinados elementos, de modo que pueden ser incluso, precedidos por el artículo definido, la cabeza de una construcción partitiva: el primero de los tres capítulos del libro. La ordenación de los miembros de una serie, al igual que la mera relación de seriación, establece un vínculo entre una expresión nominal y el discurso. Por ello, los adjetivos ordinales prenominales modifican sin problema alguno a un sustantivo elidido:

(54) a. Me ha gustado el primer capítulo. El segundo $[\mathrm{v}]_{\mathrm{N}}$ me ha aburrido. b. Acertó las dos primeras preguntas, pero falló la tercera $[\mathrm{v}]_{\mathrm{N}}$.

\section{Conclusiones}

En este trabajo he analizado las propiedades de los SsNn con núcleo elidido del español. La principal conclusión a la que cabe llegar es que la elipsis nominal está sujeta en nuestra lengua (y, probablemente, de ma nera universal) a dos condiciones semánticas, cuyos efectos se comple mentan. En primer lugar, habida cuenta de que el contenido del sustan $`$ tivo sobreentendido tiene que ser recuperado a partir de información contextual, el sintagma nominal con núcleo tácito debe estar vinculado

\footnotetext{
${ }^{35}$ En este mismo artículo se sostiene que los adjetivos ordinales posnominales son, en cambio, adjetivos relacionales clasificadores que denotan un número. Estos adjetivos, como el resto de los adjetivos relacionales (cf. § 6.2), también admiten la elipsis nominal: el capítulo primero me gusta más que el [v] $]_{N}$ segundo.
} 
con un tópico discursivo: entre los mecanismos de vinculación discursiva que permiten la recuperación del material elidido están el hecho de que el determinante que introduce un SN con elipsis encabece una construcción partitiva y que dicho determinante, o algún otro elemento determinativo, tenga naturaleza deíctica o establezca una relación de comparación, identidad, contraste, seriación u ordenación. La segunda de estas condiciones es que el resto de una expresión nominal con elipsis debe recibir una interpretación de foco contrastivo, de manera que siempre ha de aparecer o suponerse una alternativa a tales elementos focalizados en el contexto discursivo o situacional. Estas dos condiciones me han permitido dar cuenta, en concreto, de qué determinantes y clases de adjetivos admiten la elipsis nominal y cuáles la rechazan ${ }^{36}$.

No parece, en cambio, que en la formación de los ssNn con núcleo tácito del español entren en juego restricciones estructurales o estrictamente formales. La elisión del nombre con sustantivos escuetos continuos o discontinuos en plural nos indica, por un lado, que no es obligatorio que esté presente en estas construcciones un determinante que rija propiamente la categoría nuclear vacía y que tampoco se requiere que el resto del SN con elipsis contenga marcas flexivas explícitas. La existencia, por otro lado, tanto de determinantes invariables que legitiman la elipsis como de determinantes variables que no lo hacen corrobora la idea de que la aparición de marcas de género y número en el resto no es una condición ni necesaria ni suficiente para que se pueda identificar el contenido elidido.

Estas ideas tienen también repercusiones sobre el debate, al que hacía mención en la introducción, en torno a la naturaleza de las expresiones nominales del español que en estas páginas he analizado. La condición que establece que dichas expresiones nominales deben estar vinculadas con el discurso solo se puede formular si se supone que estos sintagmas incluyen el contenido de una clase de entidades que debe ser recuperado en el contexto. Este hecho entra en contradicción con la «hipótesis de la sustantivación», según la cual estas expresiones carecen de núcleo nominal. La «hipótesis de la pronominalización» nos puede ayudar a resolver este problema: dado que los determinantes serían, en tal caso, pronombres, el contenido nominal sobreentendido formaría parte de la denotación del pronombre y se podría así captar la naturaleza anafórica de estas construcciones. Sin embargo, la hipótesis de la pronominalización es incompatible con el hecho de que la elipsis nominal sea posible en SSNN con nombres escuetos continuos o discontinuos en plural (fenómeno este del que tampoco puede dar cuenta la hipótesis de la sustantivación).

\footnotetext{
${ }^{36}$ Gengel y McNay 2006 sugieren en un trabajo reciente que la partitividad o vinculación discursiva (D-linking) es un concepto derivado del hecho de que el resto de una expresión nominal con elipsis deba recibir interpretación de foco contrastivo. Dejo para futuras investigaciones el desarrollo de esta idea y su aplicación a los datos del español.
} 
La propuesta que encaja con los datos que aquí he estudiado es, por tanto, la hipótesis de la elipsis en cualquiera de sus dos versiones, el análisis con reconstrucción o el análisis con borrado. Tanto la inclusión en estas construcciones de una categoría nominal sintácticamente activa pero carente de rasgos fonológicos, cuyo contenido se reconstruye a partir de información contextual, como la aplicación de una regla fonética de borrado bajo condiciones de identidad estricta entre el material elidido y su antecedente, nos permiten expresar las propiedades anafóricas de estos sintagmas nominales y son perfectamente compatibles con el hecho de que tales sintagmas puedan no estar introducidos, en ocasiones, por un determinante.

\section{REFERENCIAS BIBLIOGRÁFICAS}

Alarcos Llorach, E. (1970): Estudios de gramática funcional del español, Madrid, Gredos.

Alonso, A, y HenríQuez Ureña, P. (1938): Gramática castellana, 2 vols., Buenos Aires, Losada (22 $2^{\underline{a}}$ reimpr., 1964).

Beck, S. (2000): «The semantics of different: Comparison operator and relational adjective», Linguistics and philosophy 23, pp. 101-139.

Bello, A. (1847): Gramática de la lengua castellana destinada al uso de los americanos, Santiago de Chile, Imprenta del Progreso. (Edición crítica de R. Trujillo, La Laguna, Universidad de La Laguna, 1981).

Bernstein, J. (1993): «The syntactic role of word markers in null nominal constructions», Probus 5, pp. 5-38.

Borer, H. (2005): Structuring sense I. In name only, Oxford, Oxford University Press.

Bosque, I. (1989): Las categorías gramaticales, Madrid, Síntesis.

- (ed.) (1996): El sustantivo sin determinación. La ausencia de determinante en la lengua española, Madrid, Visor.

- y Demonte, V. (dirs.) (1999): Gramática descriptiva de la lengua española, Madrid, Espasa.

- y Moreno, J. C. (1990): «Las construcciones con lo y la denotación del neutro», Lingüistica 2, pp. 5-50.

Bouchard, D. (2002): Adjectives, number and interfaces, Amsterdam, Elsevier.

BrIz, A. (1989): Sustantivación y lexicalización en español (la incidencia del artículo), Universidad de Valencia, Anejo IV de los Cuadernos de Filología.

Brucart, J, M. (1987a): La elisión sintáctica en español, Bellaterra, UAB.

- (1987b): «La elipsis parcial», en Demonte, V. y Fernández Lagunilla, M. (eds.), Sintaxis de las lenguas romances, Madrid, El Arquero, pp. 291-328.

— (1999): «La elipsis», en Bosque I. y Demonte V. (dirs.), vol. 2, pp. 2787-2863.

Contreras, H. (1986): «Spanish bare NPs and the ECP», en Bordelois I. y otros (eds.), Generative studies in Spanish syntax, Dordrecht, Foris, pp. 25-50.

— (1989): «On spanish empty N' and N», en Kirschner C. y DeCesaris, J. (eds.), Studies in Romance linguistics, Amsterdam, John Benjamins, pp. 83-95.

- (1992): «Descripción y explicación en la teoría lingüística. La sintaxis de los cuantificadores», Revista de Lingüistica Teórica y Aplicada (Concepción, Caracas) 30, pp. 17-38. 
- (1996): «Sobre la distribución de los sintagmas nominales no predicativos sin determinante», en Bosque, I. (ed.), pp. 141-168.

Corver, N. y van Koppen, M. (2005): «Microvariation and ellipsis in the wat voor-construction», comunicación presentada en Sounds of silence, Tilburg.

Demonte, V. (1999): «A minimal account of Spanish adjective position and interpretation», en Franco, J. y otros (eds.), Grammatical analyses in Basque and Romance linguistics, Amsterdam, John Benjamins, pp. 45-75.

Eguren, L. (1989): «Algunos datos del español en favor de la hipótesis de la frase determinante», Revista Argentina de Lingüistica 5, 1-2, pp. 163-203.

- (2008): «Clíticos léxicos y elipsis nominal», en Artiagoitia X. y Lakarra, J. (eds.), Gramatika Jaietan. Patxi Goenagaren omenez, Vitoria, Seminario de Filología Vasca «Julio de Urquijo», pp. 175-190.

- y Fábregas, A. (2005): «Cuestiones de orden: semántica y sintaxis de los adjetivos ordinales», ELUA 19, pp. 85-105.

— y SÁnchez, C. (2003): «La gramática de otro», REL 33, 1, pp. 69-122.

- y SÁnchez, C. (2004): «Contrast and addition in Romance: a case study in microvariation", en Auger, J. y otros (eds.), Contemporary approaches to Romance linguistics. Selected papers from the $33^{\text {rd }}$ linguistic symposium on Romance languages (LSRL), Amsterdam, John Benjamins, pp. 159-176.

- y SÁNchez, C. (2007a): «Grammar and history of Spanish cierto», en Kaiser, G. A. y Leonetti, M. (eds.), Proceedings of the workshop «Definiteness, specificity and animacy in Ibero-Romance languages», Fachbereichs Sprachwissenschaft der Universität Konstanz, Arbeitspapier 122, pp. 1-22.

- y SÁnchez, C. (2007b): «Imprecisión extensional e imprecisión intensional: la gramática de cierto», Verba 34, pp. 99-124.

ENÇ, M. (1991): «The semantics of specificity», Linguistic Inquiry 22, 1, pp. 1-26.

Fernández Ramírez, S. (1951): Gramática española. Los sonidos, el nombre y el pronombre, Madrid, Revista de Occidente. (Reed. con ampliaciones de J. Polo e I. Bosque, Madrid, Arco Libro, 1987).

GeNGeL, K. y McNaY, A. (2006): «Information structure and the phase level: ellipis in the DP», comunicación presentada en el Workshop on DP-internal information structure, Universidad de Utrecht.

Giannakidou, A. y Stavrou. M. (1999): "Nominalization and ellipsis in the greek DP», The Linguistic Review 16, pp. 295-331.

Gutiérrez Ordóñez, S. (1994): «El artículo sí sustantiva», Alonso, A. y otros (eds.), II encuentro de lingüistas y filólogos de España y de México, Salamanca, Universidad de Salamanca, pp. 483-507.

Gutiérrez Rexach, J. (2001): «The semantics of Spanish plural existential determiners and the dynamics of judgement types», Probus 13, pp. 113-154.

Hernanz, Maㅡ. Ll. y Brucart, J. M. (1987): La sintaxis. 1. Principios teóricos. La oración simple, Barcelona, Crítica.

Iglesias BANGO, M. (1986): «El artículo en español: aportaciones a un viejo debate», Contextos 4, 7, pp. 103-146.

Jiménez Juliá, T. (1991): «Elipsis nominal y no realización en español», en Brea, M. y Fernández Rei, F. (coords.), Homenaxe ó profesor Constantino García, Universidade de Santiago de Compostela, pp. 223-241.

Jones, M. (1993): Sardinian syntax, Londres, Routledge.

Kester, E-P. (1996): The nature of adjectival inflection, OTS dissertation series, Universidad de Utrecht. 
Kornfeld, L. y SAAB, A. (2004): «Nominal ellipsis and morphological structure in Spanish", en Bok-Bennema, R. y otros (eds.), Romance languages and linguistic theory 2002, Amsterdam, John Benjamins, pp. 183-198.

LACA, B. (1996): «Acerca de la semántica de los plurales escuetos del español», en Bosque, I. (ed.), pp. 241-268.

- (1999): «Presencia y ausencia de determinante», en Bosque, I. y Demonte, V. (dirs.), vol. 1, pp. 891-928.

- y Tasmowski, L. (2004): Différents, en Corblin, F. y de Swart, H. (eds.), Handbook of French semantics, Stanford, CSLI, pp. 109-118.

LÁzaro Carreter, F. (1975): «El problema del artículo en español», en Homenaje a la memoria de Dn. Antonio Rodríguez-Moñino, Madrid, Cátedra, pp. 347-371. (Reeditado en F. Lázaro Carreter, 1980, Estudios de lingüistica, Barcelona, Crítica, pp. 27-60).

Leonetti, M. (1999): «El artículo», en Bosque. I. y Demonte, V. (dirs.), vol. 1, pp. $787-890$.

LOBEck, A. (1995): Ellipsis: functional heads, licensing and identification, Nueva York, Oxford University Press.

—(2006): «Ellipsis in DP», en Everaert, M. y van Riemsdijk, H. (eds.), The Blackwell companion to syntax, vol. II, Oxford, Blackwell, pp. 145-173.

Longobardi, G. (1994): «Reference and proper Names», LI 25, 4, pp. 609-665.

López, L. (2000): «Ellipsis and discourse-linking», Lingua 110, pp. 183-213.

Llombart-Huesca, A. (2002): «Anaphoric one and NP-ellipsis», Studia Lingüistica 56,1 , pp. 59-90.

Martinho, F. (1998): A elipse nominal em português e em francês, tesis de maestría, Universidad de Oporto.

Masullo, P. y Depiante, M. (2003): «Gender is in the lexicon, number is in the syntax: evidence from nominal ellipsis in Spanish», comunicación presentada en el LSRL XXXIII, Indiana University.

Ntelitheos, D. (2004): Syntax of elliptical and discontinuous nominals, tesis de maestría inédita, University of California, Los Ángeles.

Pesetsky, D. (1987): «Wh- in situ: movement and unselective binding», en Reuland, E.J.y ter Meulen, A. G. B. (eds.), The representation on (in)definiteness, Cambridge, Mass, The miт Press, pp. 98-129.

Ronat, M. (1977): «Une contrainte sur l'effacement du nom», en Ronat, M. (ed.), Langue: théorie générative étendue, París, Collection Savoir, pp. 153-169.

Rooth, M. (1992): «A theory of focus interpretation», Natural Language Semantics 1, 1, pp. 75-116.

Rоoтн, M. (1996): «Focus», en Lappin, S. (ed.), The handbook of contemporary semantic theory, Oxford, Blackwell , pp. 271-297.

SAAB, A. (2004): El dominio de la elipsis nominal en español: identidad estricta e inserción tardía, tesis de maestría, Universidad Nacional del Comahue.

Sleeman, P. (1993): «Noun ellipsis in French», Probus 5, pp. 271-295.

- (1996): Licensing empty nouns in French, tesis doctoral inédita, HIL, Universidad de Leiden/oTs, Utrecht.

Ticio, M. E, (2005): «NP-ellipsis in Spanish», en Eddington, D. (ed.), Selected proceedings of the $7^{\text {th }}$ Hispanic linguistics symposium, Somerville, MA, Cascadilla Proceedings Project, pp. 128-141.

Torrego, E. (1989): «Evidence for determiner phrases», manuscrito inédito, Boston, University of Massachusetts. 